Sharif University of Technology
Scientia Iranica
SCIENTIA

\title{
A new approach to cold extrusion process: Dimples indentation on sliding contact surface and palm oil as an alternative lubricant
}

\author{
M.A. Nurul* and S. Syahrullail \\ Faculty of Mechanical Engineering, Universiti Teknologi Malaysia, UTM 81310 Skudai, Johor, Malaysia.
}

Received 14 October 2015; received in revised form 23 October 2016; accepted 8 November 2016

\author{
KEYWORDS \\ Dimples; \\ Tapered die; \\ Cold extrusion; \\ Alternative lubricant; \\ Palm oil.
}

\begin{abstract}
Surface texturing is one of the economic solutions to die modification if compared with tool change and hot works. In extrusion die design, it has become increasingly common to add dimples to maintain lubricant flow along the metal forming process. For that reason, this research was done by embedding dimples in a tapered die sliding contact surface to explore its effectiveness in a finished product of cold extrusion process. Besides, an alternative lubricant from palm oil was also tested, and mineral oil was used for comparison purposes. As a result, dimpled tapered die may help decrease the extrusion load of cold extrusion process, leading to finer surface roughness of extruded product. Palm oil-based lubricant also presents similar results to those of mineral oil, meaning that palm oil has a potential to be considered as a new metal forming lubricant in the future.

(C) 2017 Sharif University of Technology. All rights reserved.
\end{abstract}

\section{Introduction}

Tribologically, the main purpose of applying lubricant into metal forming process is to act as an agent for reducing friction and severe wear on contact surfaces [19]. Mineral oil is the most commonly used lubricants throughout industry. They are petroleum based used in applications where temperature requirements are moderate. Typical applications of mineral oils are applicable to gears, bearings, engines, turbines, etc. $[3,10]$.

Palm oil is one of the commercial vegetable oils that has a big potential to be expanded to other industries such as automotive [11], marine, bio-diesel [12-

\footnotetext{
*. Corresponding author. Tel.: +6019 7198332; Fax: +607 556-6159

E-mail addresses: m.a.nurulaini@gmail.com (M.A. Nurul); syahruls@mail.fkm.utm.my (S.Syahrullail)
}

doi: $10.24200 /$ sci. 2017.4248
14], and metal forming [7,15-18]. As a vegetable oil, it can be categorized as a renewable resource because such resources will remain as long as trees are still planted. Caminaga et al. $[15,16]$ successfully conducted an experiment using various types of potential plantbased lubricants, and found that the surface roughness and the dimensional quality of the products extruded with these alternative lubricants are similar to those found in the standard tests.

As mentioned earlier, lubrication is fundamentally used to control wear and friction between two contact surfaces. An alternative approach has been implemented by few researchers to maintain a lubricant flow along the metal forming process. Surface texturing is among the low-cost solution to modification die if compared with tool change, hot works, and others. In extrusion die design, it has become increasingly common to add micro-pits to balance the metal flow. The balance of metal flow is particularly important for multiple cavity dies or sections with varying thickness in order to maintain a uniform velocity profile across 
the face of the die, thus minimizing distortion of the extrudate [19]. Initially, micro-pits, also known as pocket die, was designed for the manufacturing of a long and continuous profile by welding the subsequent billet transversely to the last billet remaining in the pocket. In this way, the extrusion process is run in a semi-continuous fashion, leading to the reduction of downtime and increased productivity [20].

Through an appropriate selection of lubricant, manufacturers can produce either smooth or rough surface depending on the demands. Changes in lubrication can alter the mode of deformation during the forming processes and change the mechanical properties of the final product. Since the benefits of friction and lubrication control can be immense in metal forming, especially cold forming, considerable effort has been directed to the measurement of friction for both general metal working conditions and specific metal working processes so far [5].

Additionally, surface texturing of a tool is one of the important tribological parameter in controlling metal forming processes. The micro pits, also known as oil pockets, holes, dimples, or cavities, may reduce friction in two ways: by providing a lift as a microhydrodynamic bearing and also by acting as a reservoir of lubricant [20-24]. Surface texturing is also successfully applied to mechanical seals resulting in an increase in real life. Textured surfaces can provide traps for wear debris in dry contacts subjected to fretting wear resistance and almost doubling the fretting fatigue life $[25]$.

Thus far, a number of studies have highlighted the factors associated with maintaining the lubricant flow. Galda et al. (2009) examined the influence of surface texturing on sliding lubrication by means of a Stribeck curve [26]. The study showed that proper shape and dimensions, as well as suitable area density of oil pockets, could improve the friction characteristics of the sliding pairs in comparison to non-textured surfaces.

The research by Norhayati et al. (2012) also found that micro-pits on the tapered die sliding surface are able to control the frictional constraint compared to those surfaces without micro-pits [27]. Furthermore, Sudeep et al. (2013) concluded that there are significant reductions in the coefficient of friction and vibration at the lubricated concentrated points of contact in surface texturing [28].

In recent years, a few authors have begun to perform numerical analyses and to compare them with experimental investigations. In 2011 and 2012, Reizer et al. revealed that the results of the simulation of worn surface topography on a block-on-ring tester matched the results obtained from experimental methods $[29,30]$.

By considering the importance of surface modifi- cation and good lubrication in metal forming process, this research is conducted to study the effect of a dimpled tapered die on cold-work plane strain extrusion process. It is then compared with a non-dimpled tapered die in order to ensure whether the dimpled surface gives a big impact towards better surface roughness of sliding contact area, minimizing extrusion load, and at the same time reducing friction and wear along the extrusion process. In addition, this research also intends to identify the alternatives of mineralbased lubricants for metal forming by considering a non-edible palm oil-based lubricant as a test. Besides cooking oil, there are a numerous potential applications of palm oil which need to be explored. This study, hopefully, would help to promote more applications of renewable natural resources as well as to protect the environment.

\section{Material and methods}

Figure 1 illustrates the research flow overviews of the study. This research was conducted to examine the effects of a dimpled surface tapered die sliding contact surface. The experimental surface of tapered die was indented with micro dimple using dot peen marker. It was then compared with a non-dimpled tapered die. The constant parameters for dimple are the depth, shape, and diameter. Two types of lubricants were chosen as the supply lubricant during cold work extrusion process in order to analyze the tribological effect in the study. A detailed elaboration on the methodology of tapered die and billet was included in the next section accordingly.

\subsection{Tapered die preparation and textured surface design}

Tapered dies are made in two conditions. As shown in Figure 2, dimpled tapered die on contacting surface is designated as ' $\mathrm{A}$ ', while the non-dimpled tapered die is designated as ' $\mathrm{O}$ ' and used for comparison purposes. Each textured hole is spherical in shape with diameter $0.2 \mathrm{~mm}$ and $0.03 \mathrm{~mm}$ in depth. The distance between the holes is kept the same, with $1 \mathrm{~mm}$ vertically and horizontally. All those parameters (shape, diameter, depth, and distance) were chosen due to the availability of machine in a laboratory. Additionally, right after the experiment, the entrapped debris inside the dimples is able to measure the optimum size of dimple by microscopic observation and other analyses.

All tapered dies in this research are made of tool steel JIS SKD11. This type of tool steel is categorized as a high-carbon and high-chromium alloy tool steel. It offers longer tool life with good wear resistance and size after heat treatment. The original hardness is approximately at $381.0 \mathrm{Hv}$, making it tough and suitable for making long-life high-precision cold-work 


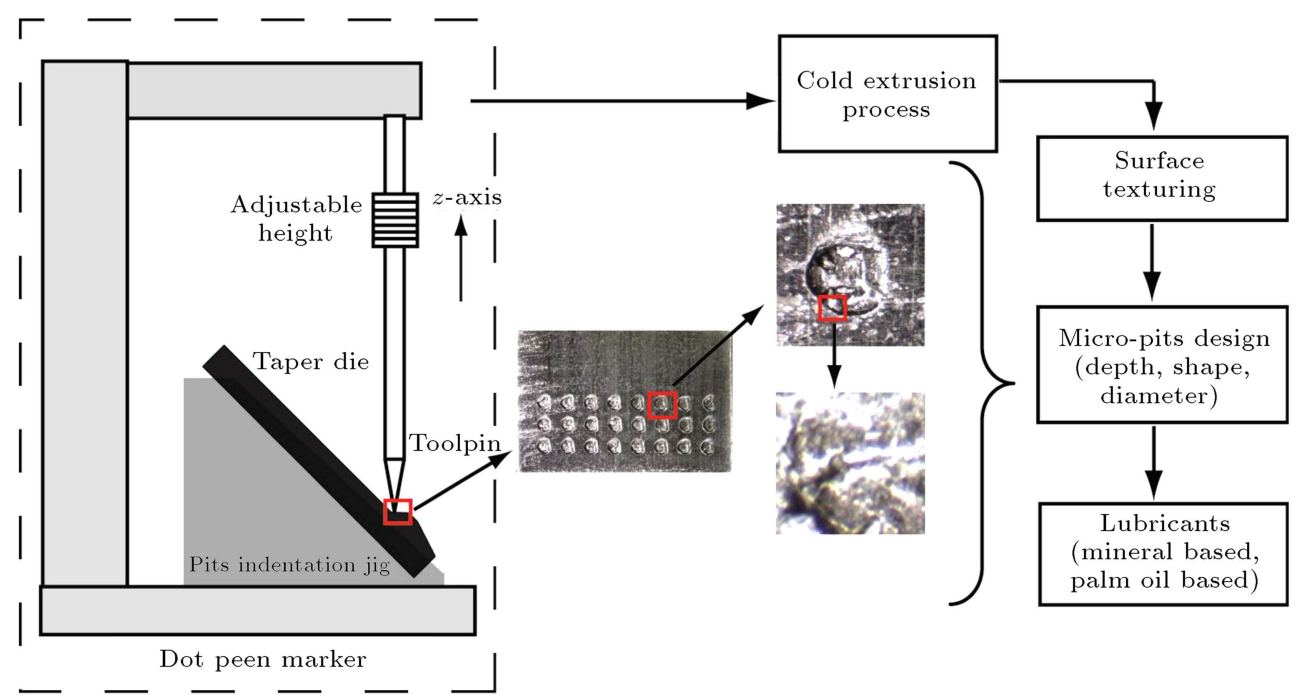

Figure 1. Experimental condition of research.
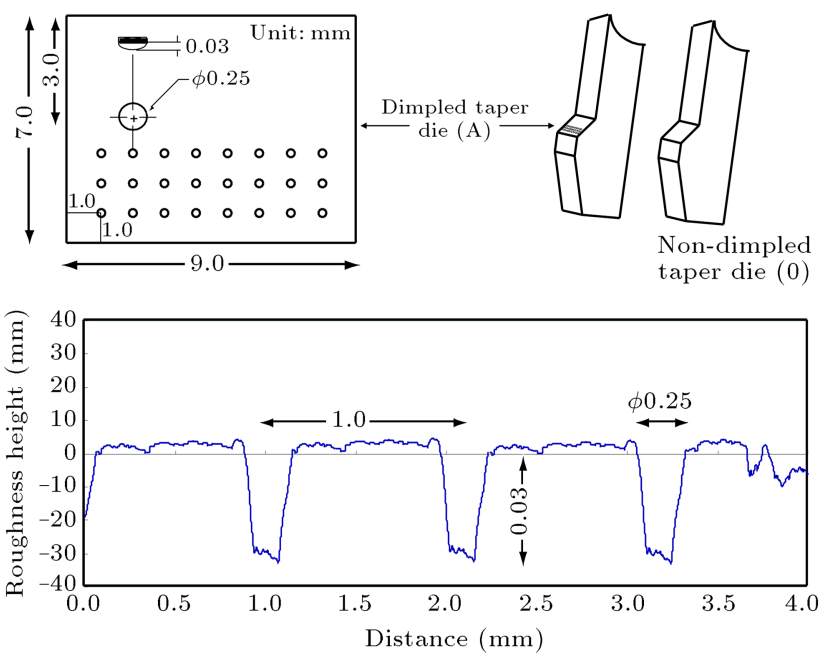

Figure 2. Schematic of surface textured indentation.

dies. After the specimens are machined according to specific dimensions, the tapered area is textured using a dot peen marker. This marking machine uses tool steel punch as a marking tool. $x$ and $y$ directions were controlled automatically by an integrated control unit, while the micro-pits depth is controlled by $z$-direction manually.

Following texturing, the specimens are hardened until the temperature reached $1030^{\circ} \mathrm{C}$ for more than 5 hours and cooled in the open air until it reaches the room temperature. The hardness of the material after heat treatment is $825.2 \mathrm{Hv}$.

The final step in making the specimens is polishing. The surface roughness of tapered die before polishing (roughness after hardening process) is approximately 2.0 microns. Notably, surface polishing after surface texturing and hardening processes removes all the surface protrusions around the textured hole that appeared during texturing and provides a super fine surface finish. A smooth and polished die surface is desirable for liquid lubricants, where any remaining roughness is preferably oriented in the direction of material flow. The polishing area is a surface which is in contact with billet during an experiment. The experimental surfaces of the tapered die (surface in contact with the billet) were polished with abrasive paper, and an arithmetic surface roughness, i.e. Ra of approximately $0.15 \mu \mathrm{m}$, was recorded. Moderate roughness of the work piece surface helps to carry liquid lubricants into the interface, especially if the roughness is perpendicular to the direction of feeding [31].

\subsection{Experimental apparatus}

Figure 3 shows a schematic sketch of cold work, vertical, forward extrusion process used in the experiment. The main components are container, tapered die, and billets. The die half angle of the tapered die used is $45^{\circ}$, as shown in Figure 3(a). The tapered dies are made of tool steel (SKD11), and necessary heat treatments were performed before the experiment. The extrusion ratio is $3: 1$.

This experiment was carried out with the laboratory press machine at room temperature. This plane extrusion apparatus was assembled and placed on the load cell to record the load extrusion ( $Y$-axis) during each test. The displacement of ram stroke ( $X$-axis) was also recorded by using the displacement sensor, attached to the holder of plain extrusion apparatus. Extrusion stopped at a piston stroke of $35 \mathrm{~mm}$, where the extrusion process was expected to reach a steady state. The ram speed was constant at $7.6 \mathrm{~mm} / \mathrm{s}$. Lubricant was applied onto the tapered die (surface which has contact with the billets) before the test. The billets were cleaned with acetone. During the extrusion process, the two similar billets were stacked and used as one unit of billet fixed on a container and extruded 


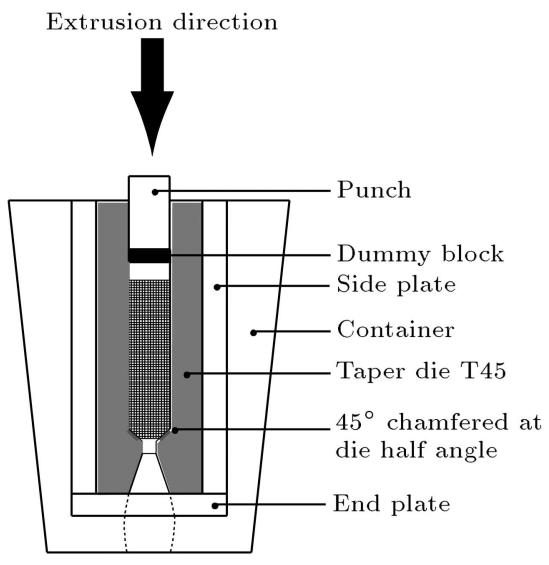

(a)

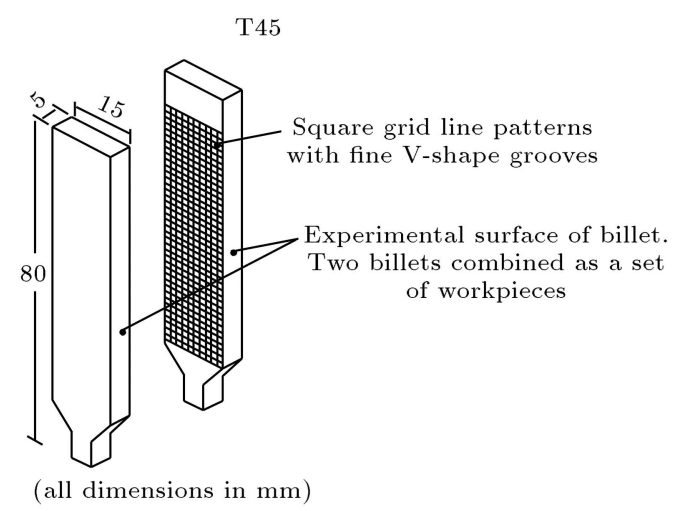

(b)

Figure 3. (a) Schematic of plane strain extrusion apparatus. (b) Schematic for billet used in the experimental works.

through a pair of tapered die. After the experiment, the partially extruded billets were taken out from the plane extrusion apparatus, and surface roughness of the billet with the observation plane was measured. Then, the extrusion load was analyzed.

Figure 3(b) shows a schematic sketch of the billets used in the experiment. The billets' materials are made of pure aluminium (A1100). The billets are shaped by an NC wire cut electric discharge machining device. Two similar billets were stacked and used as one unit of billet. One side of the contact surface of the combined billets was the observation plane of plastic flow in plane strain extrusion. The observation plane was not affected by the frictional constraint of the parallel side walls. A square grid pattern measuring the material flow in the extrusion process was scribed by the NC milling machine on the observation plane of the billet. The grid lines were $\mathrm{V}$-shape grooves with $0.5 \mathrm{~mm}$ depth, $0.2 \mathrm{~mm}$ width, and $1.0 \mathrm{~mm}$ interval length. The billets were annealed before the experiment to remove the residual effect, coming from the preparation of billet before undergoing any cold work extrusion process.

\subsection{Lubricants}

Besides adding dimple onto tapered die surface, the objective of this research is to explore the possibility of using palm oil as a substitute for industrial oil in extrusion process. The alternative lubricant used in this study was Refined, Bleached, and Deodorized (RBD) palm stearin, while the mineral oil used for comparison purposes was Paraffinic Mineral Oil (PMO) VG95 and VG460. RBD palm stearin is a more solid fraction obtained by fractionation of palm oil after crystallization at controlled temperatures. So, palm stearin is a very useful source of fully natural hard fat component for products such as shortening and pastry and bakery margarines, and also possesses suitable properties for making soaps and formulating animal feeds.

Mineral oil will be used as a benchmark in finding out the similarities between the two different types of lubricant so as to check whether vegetable oil has the potential to be chosen as an alternative metal forming lubricant or not. Mechanical properties of tested lubricants, such as density and kinematic viscosity, are presented in Table 1. The kinematic viscosity is recommended when dealing in fluid motion and velocity field. It may notify the propagation of the movement by friction.

All the values in Table 1 were tested using viscometer. Starting at laboratory temperature (more or less $24^{\circ} \mathrm{C}$ ), two hundred fifty milliliters of lubricant was measured and heated by a heater until its temperature

Table 1. Mechanical properties of testing lubricants.

\begin{tabular}{|c|c|c|c|c|}
\hline \multicolumn{2}{|c|}{ Mechanical properties } & $\begin{array}{c}\mathrm{RBD}^{\mathrm{a}} \text { palm stearin } \\
(\mathrm{P} 1)\end{array}$ & $\begin{array}{l}\text { PMO VG95 } \\
\text { (M2) }\end{array}$ & $\begin{array}{c}\mathrm{PMO}^{\mathrm{b}} \mathrm{VG} 460 \\
\text { (M3) }\end{array}$ \\
\hline Relative density, & $\rho$ & 0.870 & 0.850 & 0.860 \\
\hline \multirow{3}{*}{$\begin{array}{l}\text { Kinematic viscosity, } \\
\qquad\left(\mathrm{mm}^{2} / \mathrm{s}\right)\end{array}$} & $27^{\circ} \mathrm{C}$ & 48.29 & 249.95 & 1374.60 \\
\hline & $40^{\circ} \mathrm{C}$ & 38.01 & 71.75 & 411.25 \\
\hline & $100^{\circ} \mathrm{C}$ & 8.56 & 13.40 & 28.10 \\
\hline
\end{tabular}

${ }^{\mathrm{a}} \mathrm{RBD}=$ Refined, Bleached, Deodorized

${ }^{\mathrm{b}} \mathrm{PMO}=$ Paraffinic Mineral Oil 
reached $100^{\circ} \mathrm{C}$. Then, the heater was switched off to let the tested lubricant cool down slowly to room temperature. All the data were recorded by software according to the programmed database. One drop of lubricant (approximately $15 \mathrm{mg}$ ) was applied onto the experimental surface of a tapered die before the experiment. The initial amount of the lubricant was predicted to create full film lubrication regime at the early stage of the extrusion process.

\subsection{Experimental procedure}

The plane strain extrusion apparatus was assembled and placed on the press machine. The forming load and displacement data were recorded by computer. The experiments were carried out at room temperature. Extrusion was stopped at piston stroke of $35 \mathrm{~mm}$ with constant ram speed and constant ram hydraulic pressure at 120 bar. After the experiment, the partially extruded billets were taken out from the plane strain extrusion apparatus and the combined billets were separated for the surface roughness measurement.

\section{Results and discussions}

\subsection{Extrusion load}

The extrusion load-piston stroke curve is shown in Figure 4 . The figure shows that the extrusion load has reached a constant level during the process and a steady state has been observed at the piston stroke of $15 \mathrm{~mm}$ onwards for dimpled tapered die (A). Non-dimpled tapered die samples show an unstable condition from the beginning until the end of the process. Thus, all the curves show a reduction in extrusion load once the maximum load is reached. This trend may be due to the fact that the frictional force decreases linearly once the maximum load is reached, as proposed by Noorani et al. [32]. The maximum extrusion load values for P10 , M2-0, and M3-0 are $58.70 \mathrm{kN}, 60.22 \mathrm{kN}$, and 48.92 $\mathrm{kN}$, respectively, while $\mathrm{P} 1-\mathrm{A}$ extrusion load at $40 \mathrm{~mm}$ is $46.15 \mathrm{kN}$ for dimpled tapered die (A), followed by M2-A at $49.02 \mathrm{kN}$ and M3-A at $49.30 \mathrm{kN}$. PMO VG95 shows higher extrusion load, either with dimpled or non-dimpled tapered die. For non-dimpled tapered die, it shows unsteady-state condition of extrusion load. It was due to the fact that sharp edges at the die half angle of the tapered dies squeezed out the lubricant more than the modified tapered die. This phenomenon leads to a more metal-to-metal contact between sliding surfaces of tapered die and billet, resulting in higher extrusion load.

Consistently, PMO VG460 shows the lowest extrusion load, either by non-dimpled or dimpled condition, if compared to other test lubricants. In addition, the viscosity is also lower because the lubricant is thicker and more concentrated. RBD palm stearin also shows low extrusion load for dimpled tapered die, instead of its non-dimpled condition. Viscosity of RBD palm stearin is not as high as PMO VG95 and PMO VG460, but still the highest among renewable lubricants, especially among palm oils. RBD palm stearin is in a semi-solid state at room temperature and will fully liquidize when it reaches $40^{\circ} \mathrm{C}$ so that it may slow down the motion during the extrusion process. Due to the physical condition, it will result in less friction and less extrusion load during extrusion process [22]. Therefore, a lesser metal-to-metal contact between billet and tapered die was observed [23]. Liliang et al. [33] also said that a lubricant is suitable to be applied to contact area during extrusion process if the lubricant used can minimize the extrusion load to a reasonable range. PMO VG95 seems to have more contact with sliding surface, and it is proven that when more metal-to-metal contact occurs, the process needs more energy to shear the material and increase extrusion load.

Extrusion equipment mainly includes presses, die, and tooling. Most of extrusions are made with presses. So, minimizing extrusion load with the use

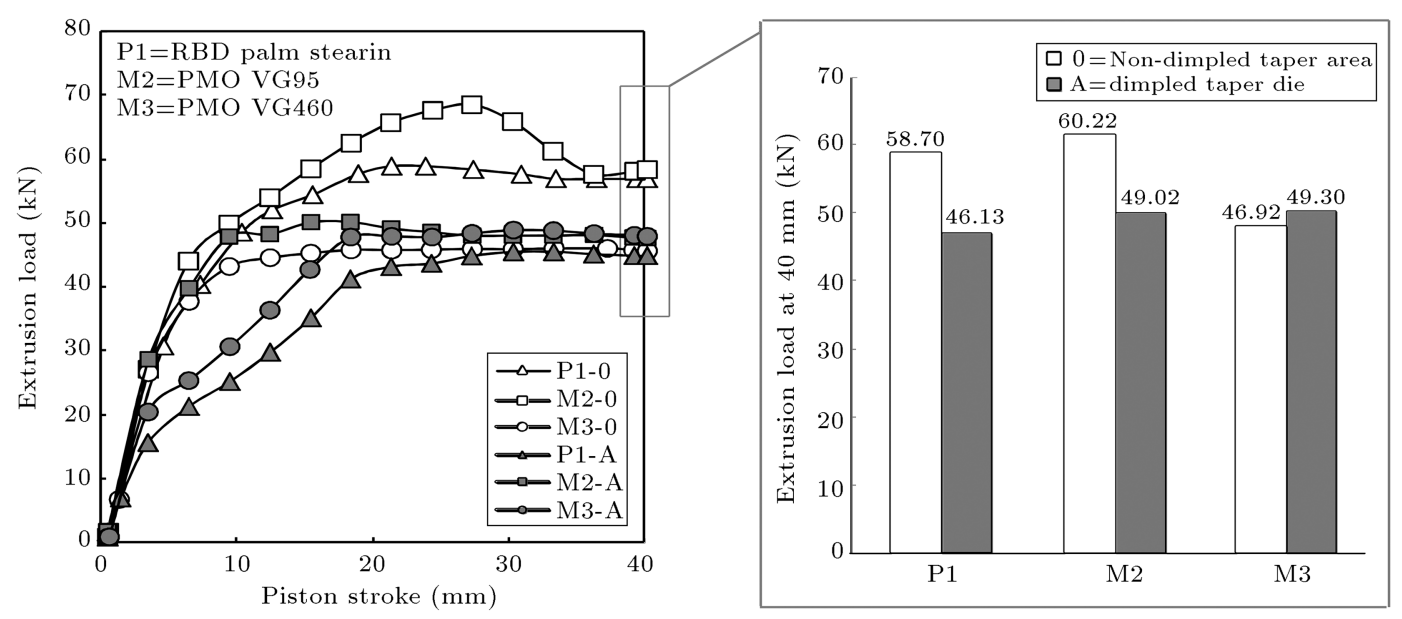

Figure 4. Schematic sketch of the hydraulic press machine. 
of proper lubricant during the process is such a big concern to industries in a way that it can extend the lifespan of machines. From the findings, RBD palm stearin is one of the alternatives that can be considered as a metal forming lubricant, especially in extrusion process, where its kinematic viscosity in room temperature is $249.95 \mathrm{~mm}^{2} / \mathrm{s}$ (refer to Table 1). Due to its high viscosity (among palm oil categories), a thick film is able to tolerate the extrusion force. Its characteristics are similar with those of the preferred existing metal forming lubricants so that boundary lubrication between two surfaces can be created [25]. It contains fatty acid that helps to maintain the thin lubrication layer between tapered die and billets $[5,34]$. According to Yingying et al. [35], with the increase of FFA, the yield of glycerol decreases slightly. Glycerol normally will react together with fatty acid to create a thin layer between sliding actions. This reaction reduces friction, wear, and extrusion load. The more glycerol and fatty acid, the thicker the layer.

Dimpled surface at tapered die sliding contact was proved able to reduce extrusion load, rather than non-dimpled $[7,11,22]$. The type of surface provides traps for lubricant flow during extrusion process, as it can also hold the lubricant slightly longer in order to maintain the surface roughness quality until the product area.

\subsection{Surface roughness}

The distribution of arithmetic mean surface roughness, $\mathrm{Ra}$, along the experimental surface billet (sliding plane) was measured with a surface profiler device. The experimental surface was defined as the surface of billet which was in contact with a tapered die and a container during the extrusion process. Un-deformation area is a region of the billet which does not deform during the extrusion process. The region of the billet that started to deform according to the shape of the tapered die during the extrusion process is categorized as deformation area, while product area is the region of the billet which is extruded from the tapered die bearing (just passed the tapered die angle during extrusion process). The measured direction is perpendicular to the extrusion direction. The product areas $(0 \mathrm{~mm})$ and deformation area $(8 \mathrm{~mm})$ for both types of tapered die are tested for wear observation in billet which will be discussed in the next section.

Figure 5 presents the roughness value for product and deformation area, respectively. For the nondimpled tapered die (0), PMO VG460 is rougher, rather than PMO VG95 and RBD palm stearin. At the

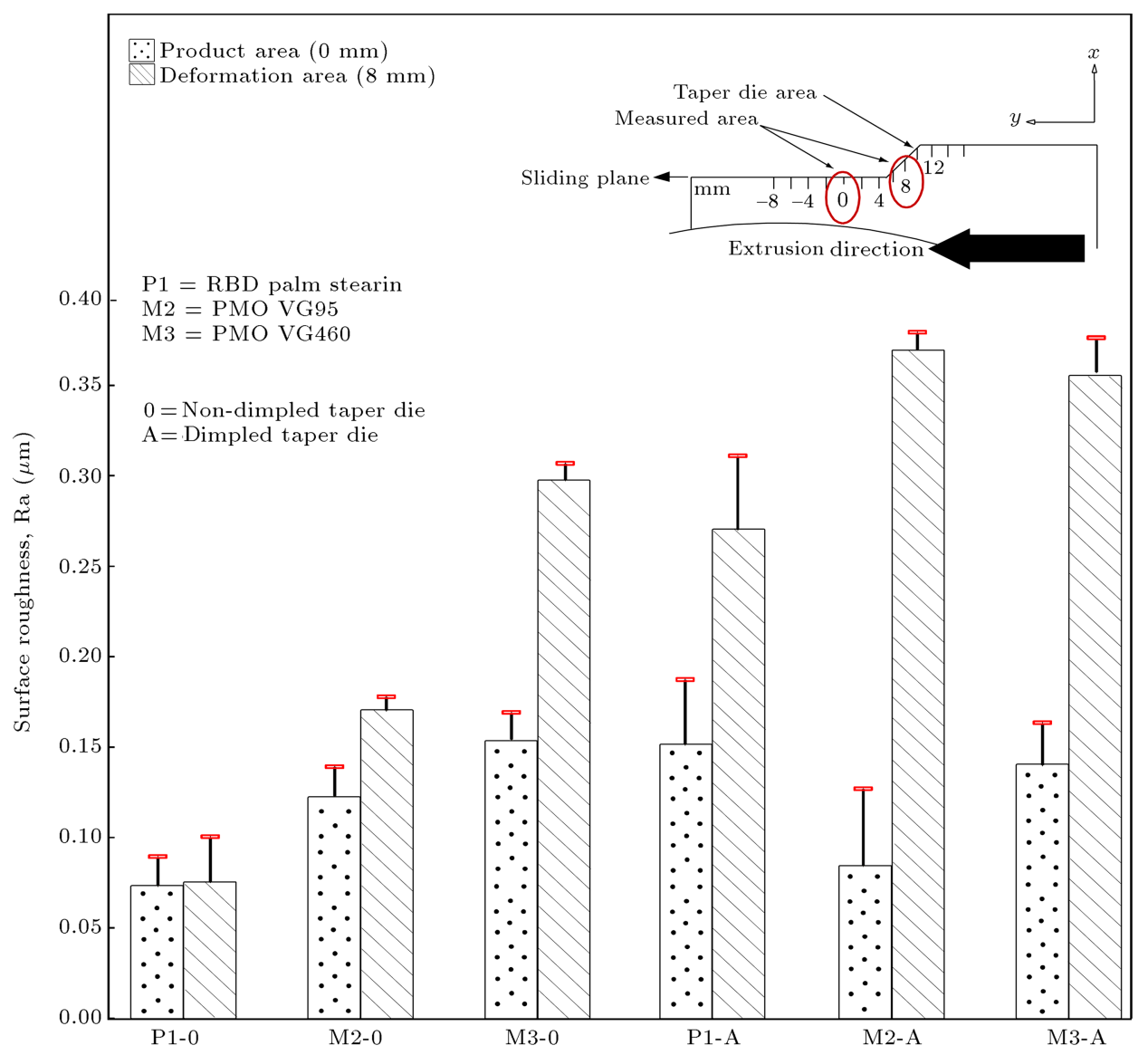

Figure 5. The roughness value for product and deformation area. 


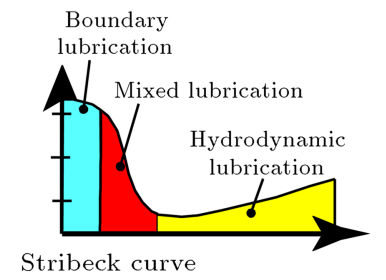

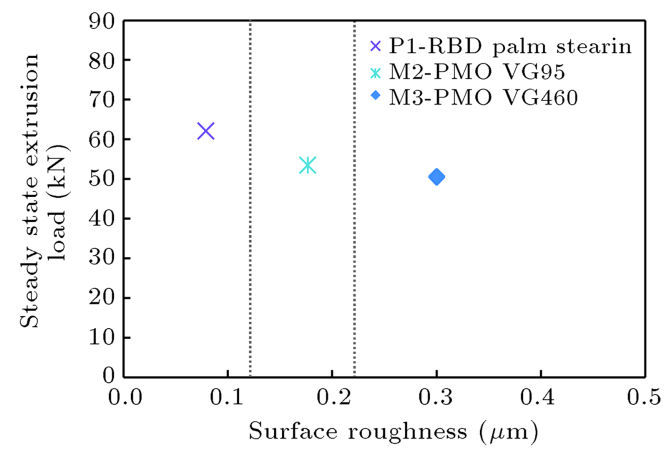

(a)

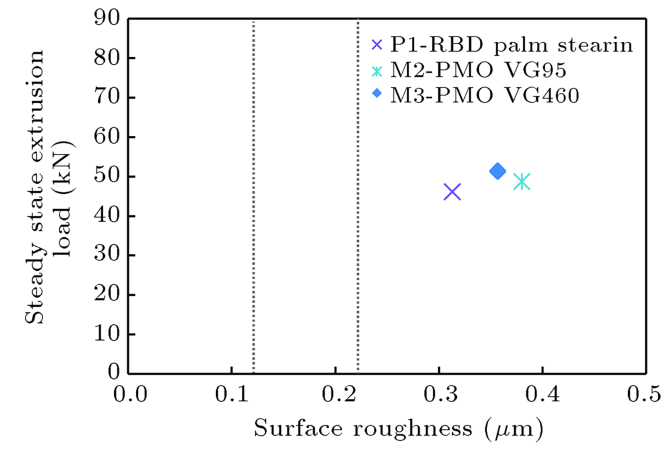

(b)

Figure 6. Steady-state extrusion load against surface roughness at deformation area of extruded billet for (a) non-dimpled and (b) dimpled tapered dies.

product area, roughness value for M3-0 is $0.153 \mu \mathrm{m}$, followed by M2-0 and P1-0 with $0.122 \mu \mathrm{m}$ and $0.073 \mu \mathrm{m}$, accordingly. Because of the thick layer from the very beginning of deformation process, the thin film tends to stay on the sliding surface. The thicker film layer separated the surface between the tapered die and billet. It may prevent the asperities of billet to be further flattened by surface of die [36-38]. With regard to the solid contact between sliding contact surfaces, a reduction in the solid contact area may decrease friction $[39,40]$.

The values are getting smoother with dimples existence for M2 lubricant on the tapered die's sliding surfaces, which show a reduction of roughness. As shown in Table 1, M2 is the lowest viscous lubricant among all test lubricants. Due to the high liquidity of lubricant, the decreasing roughness in this region is most probably due to the highest contact pressure in this region, as proposed by Tiernan et al. [41]. As dimples were embedded in the measurement area, it was proven that better surface roughness can be obtained. Some amount of lubricant might be entrapped during the process inside the dimples, but it still gives a good impact for smoother sliding surface, rather than without embedded dimples.

From the beginning of the extrusion process, it shows a stable value of each tested lubricant. As predicted, sliding contact surface by using dimpled tapered die (A) presents the finest surface roughness and yet, finer than at the deformation area. Wakuda et al. [38] and Sudeep et al. [42] verified that surface texturing is one of the effective keys to friction reduction. With an existence of textured surface at the tapered die area, again, it is an advantage for a better surface roughness along the sliding contact area. Nevertheless, the difference between each lubricant is not significant at a range of 0.1 to 0.25 microns.

As presented in Figure 6(a), non-dimpled tapered die condition creates a normal view of Stribeck Curve in deformation area. RBD palm stearin (P1) creates a boundary lubrication as the Free Fatty Acid (FFA) sticks strongly to the contact surface between tapered die and extruded billets. It is then followed by PMO VG95 (M2) and PMO VG460 (M3) in mixed lubrication regime, while, for dimpled tapered die in Figure 6(b), the dimple location at the bottom part of taper angle creates a transition condition of lubrication regime between mixed and hydrodynamic lubrication regimes to all the tested lubricants. By comparing non-dimpled and dimpled tapered dies, the difference is at the surface roughness value where dimpled tapered die condition results in higher roughness than nondimpled tapered die. As the highest value of surface roughness on dimpled tapered die condition, still no severe wear was observed in the product area of extruded billets that may create crack, fracture, or any material failures.

\subsection{Metal flow observation}

Flow line is used to study the metal flow during the extrusion. During the extrusion process, the magnitude of the frictional force affects the metal flow significantly. The area where frictional force is lower will flow faster than that with higher frictional force [22]. Therefore, the grid lines on the billet after the extrusion would look like travelling toward the die in wave profiles. This is due to the fictional force that is created between the billet and tapered die 
contact which drags the side of billet, prompting the metal flow faster in the middle part of the billet. The higher the fictional force, the bigger the distortion. According to Solomon and Solomon [43], for a cylinder shape extrusion, the most deformed metal layer after the extrusion are the layers located between the outer surface and the half of the radius.

Figure 7 presents a grid-line pattern on the

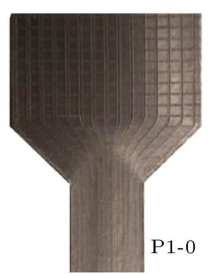

P1-RBD palm stearin

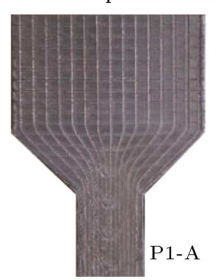

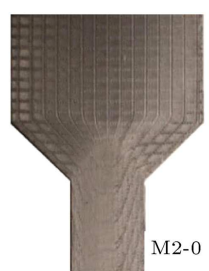

M2-PMO VG95

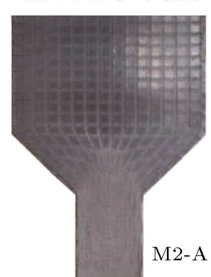

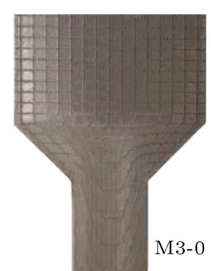

M3-PMO VG460

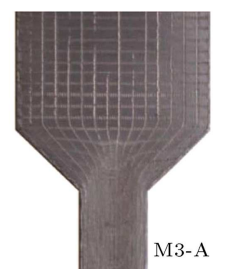

Figure 7. Grid-line pattern on the plastic flow observation surface of the billet.

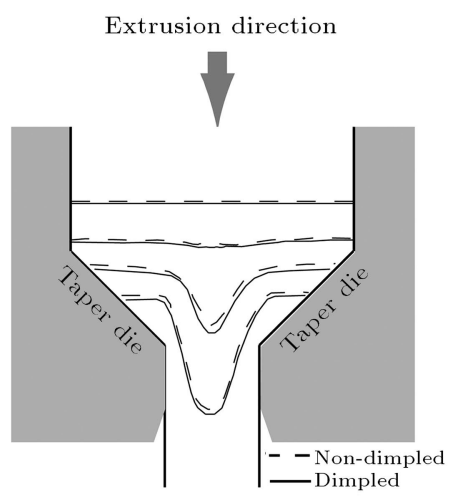

RBD palm stearin

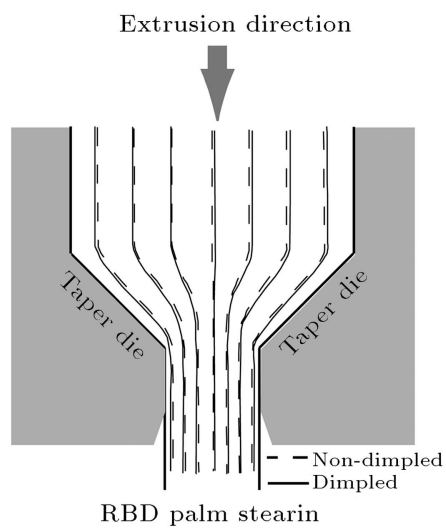

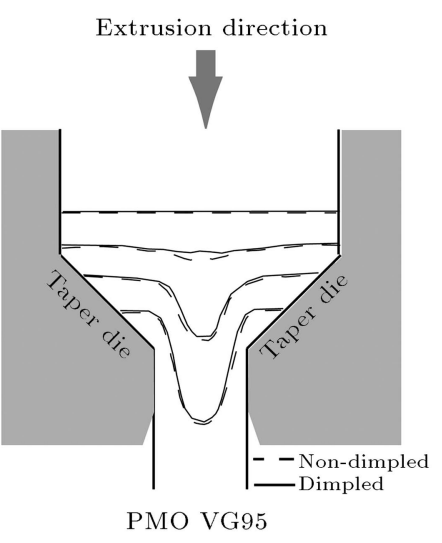

(a)

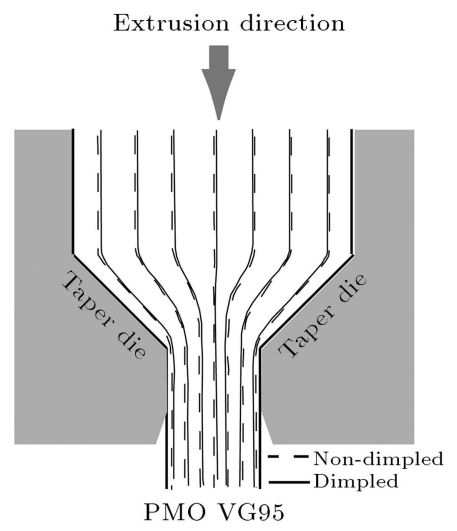

(b) plastic flow observation surface of the billet after being removed from the extrusion rig. There are a total of 17 horizontal lines drawn on the billet. The observation flow line will cover the edge side of extruded billet, which is located at the deformation area. The grid lines in parallel with extrusion direction are defined as horizontal lines, whereas the lines perpendicular to the direction of extrusion are defined as vertical lines. Both lines were copied into digital data, and then all the collected data were recalculated and repositioned at a constant distance from the billet's un-deformation area.

Figure 8(a) and (b) exhibit the mutual comparison of vertical and horizontal grid lines. As mentioned earlier, PMO VG95 created a slightly higher friction between tool and the billet surface, causing the billet to deform more than usual during the extrusion process [44]. By comparing this finding with metal flow observation, it is proven that PMO VG95 has more metal-to-metal contact as the result was significant compared to RBD palm stearin.

According to Mariana et al. [45], the metal flow pattern in extrusion depends on the local friction conditions and geometric shape dies. In other words, since the tapered die used for all experiments is the
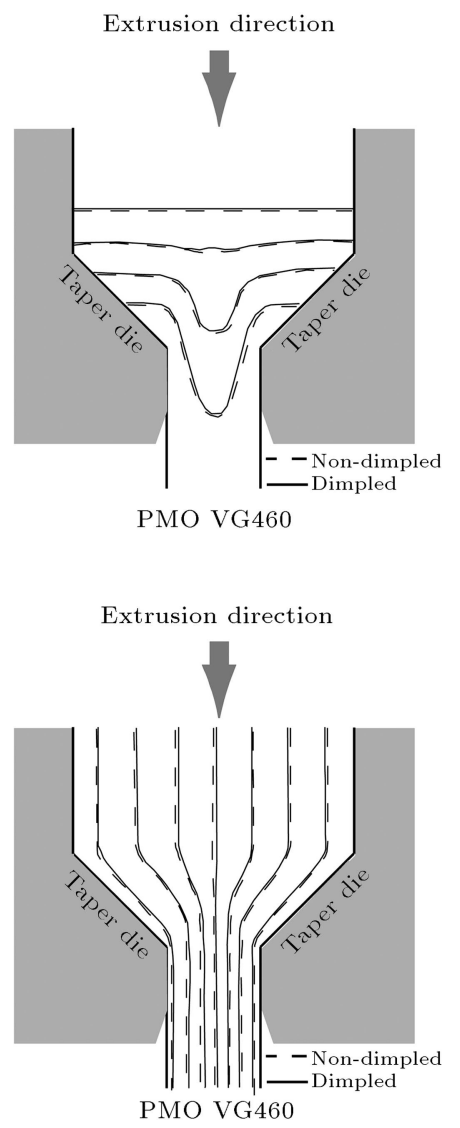

Figure 8. (a) Mutual comparison of vertical grid lines of extruded billet surfaces. (b) Mutual comparison of horizontal grid lines of extruded billet surfaces. 
same, there is no influence of metal flow pattern due to the difference in die shapes. Two types of frictions were developed during the extrusion process. They are sticking friction at the container surface and shear strength friction within the material layers itself, as proposed by Qamar et al. [46]. They explained that the difference in metal flow pattern during extrusion is due to the dominant friction during the extrusion process.

\subsection{Observations (tapered die and billet)}

Figure 9 presents the surface image of dimpled (A) tapered die captured by a CCD camera. Charge Couple Device (CCD) camera is used to capture the images with a magnification of 4.5 ; based on the observation, it was found that no severe wear has occurred. The tapered die surface conditions before and after the extrusion process were clearly visualized. The shiny silver color inside the holes indicates the amount of entrapped debris coming from the billet during the process. From the figure, RBD palm stearin is entrapped more into the holes, rather than PMO VG95. The findings confirmed that lubricant with thin thickness may lead to a higher friction and extrusion load, as well as causing the deformation process to be higher compared to lubricant with thick thickness.

Billet observation is done at the product area. Figures 10(a) and (b) present an image of extruded billet using both conditions of the tapered die. The analyzed areas for both types of tapered die are the same areas used for surface roughness test, discussed earlier.

As shown in both figures, the severity of wear on an extruded billet using dimpled tapered die was found to be less compared to the non-dimpled tapered die. It was probably due to better lubrication presented by
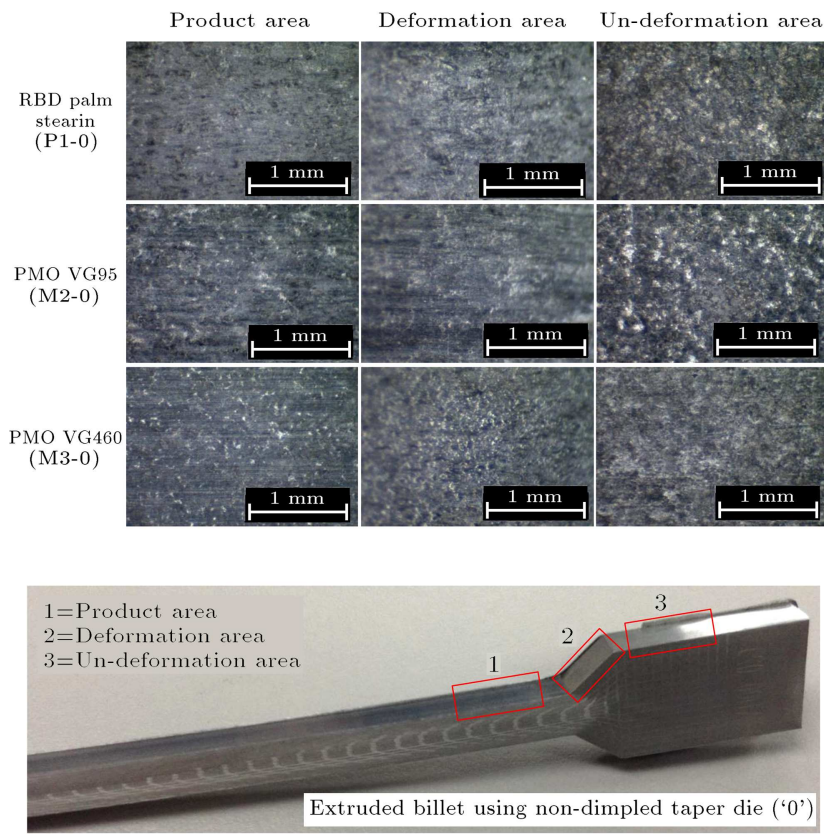

Figure 10(a). CCD images of extruded billet using non-dimpled tapered die (0).

micro holes through oil reservoir action. In addition, holes could have acted as micro-cavity for wear particles generated during reciprocating sliding motion of lubricated concentrated contacts [45].

For less viscous lubricant, more metal-to-metal contact between sliding surface occurs, resulting in higher friction and wear. The increment in real contact area is able to produce smoother surfaces, while lesser contact area results in rougher surfaces due to asperities interlocking. Nevertheless, there is no significant differences in the surface roughness, as the results vary in the range between 0.1 and 0.25 microns (see Figure 5). It also shows the image of billet before

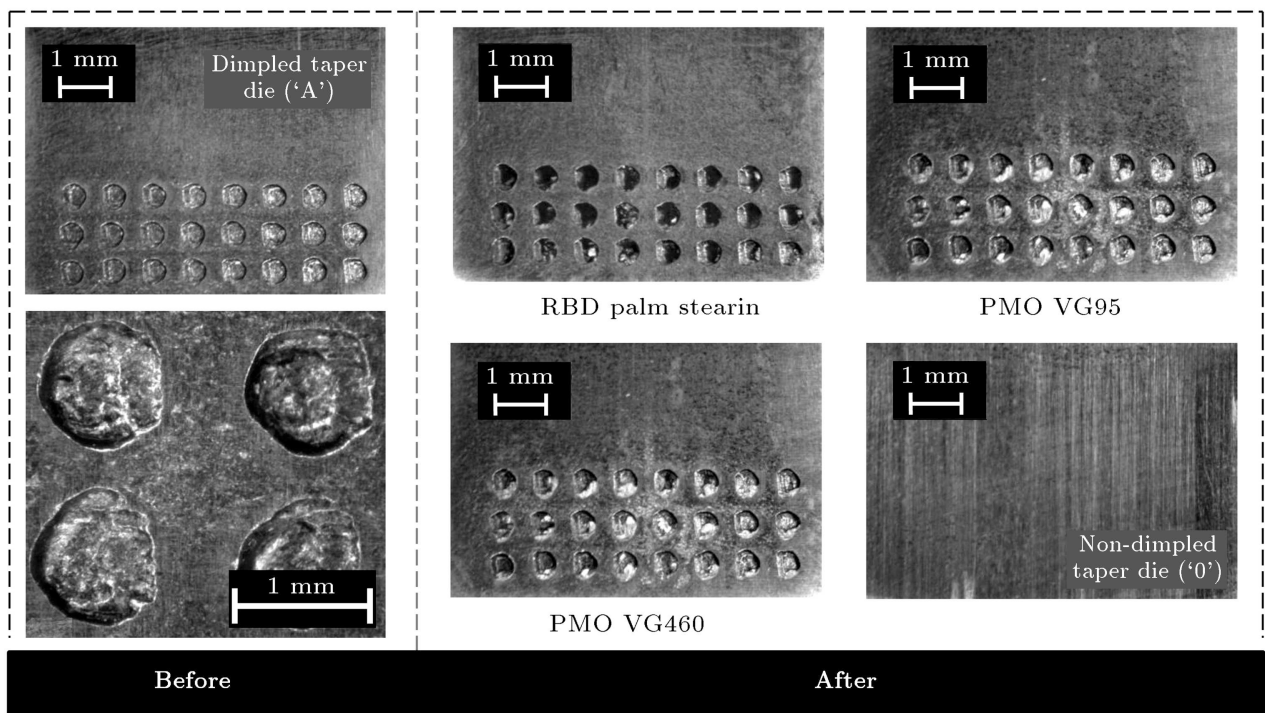

Figure 9. Surface image of dimpled tapered die (A). 

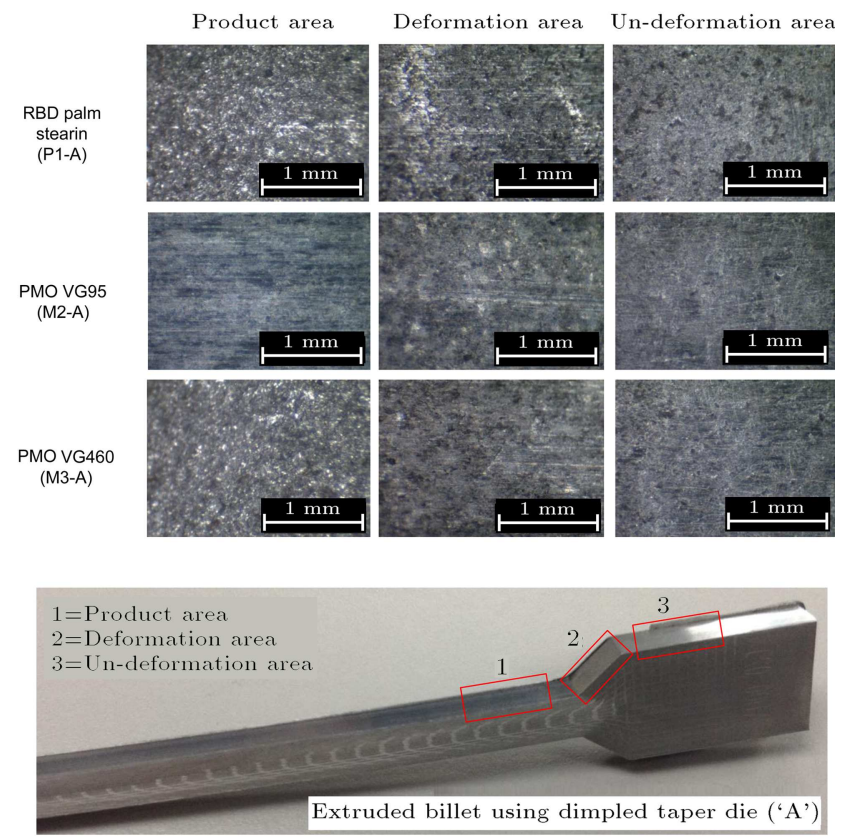

Figure 10(b). CCD images of extruded billet using dimpled tapered die (A).

experiment, in which it was a region of the billet where the cross-sectional area does not undergo any changes in size, or not affected by extrusion process.

\section{Conclusions}

The main purpose of this study is to find alternative approach in order to maintain lubricant flow along the extrusion process. In addition, finding the alternatives to mineral-based lubricant for metal forming process was done effectively. Hence, a study was conducted by comparing dimpled (A) and non-dimpled (0) tapered die sliding surfaces using cold extrusion process on A1100 pure aluminium billet. The alternative lubricant was chosen from palm oil-based lubricant, RBD palm stearin, together with the existing mineral oil, PMO VG95 and PMO VG460. The tribological behaviors of extruded billet and tapered dies were compared and analyzed accordingly. The following conclusions can be drawn based on the results of experimental tests:

1. The visual experiments show that the dimpled tapered die may help to decrease the extrusion load of cold extrusion process. Dimpled tapered die on sliding surface area is able to entrap more lubricant during extrusion process, while preventing more metal-to-metal contact between a billet and tapered die. It also produced lower friction and wear. Lubricant with less viscosity not only creates higher friction, but has also an advantage at the same time which may lead to better surface roughness. It could be due to fact that lubricant with thin thickness tends to produce more contact between sliding surfaces, and yet resulting in finer surface along the contact area;

2. Debris entrapped inside the textured holes does not present high influence towards the performance of metal forming product. No severe wear was observed which may lead to other material failures such as crack, fracture, and fatigue;

3. Due to high viscosity, the palm oil-based lubricant tends to have similar attributes to the recommended mineral oil in terms of its lesser extrusion load and friction.

Generally, extrusion using mineral-based lubricants requires lower maximum extrusion load compared with plant based lubricants. However, the lubricity of the RBD palm stearin is comparable to PMO VG460 (commercialized lubricant in industry). Therefore, RBD palm stearin is likely to replace paraffinic mineral oil as the commercial lubricant in metal forming processes, as far as its required maximum load is concerned.

\section{Acknowledgements}

The authors wish to thank the Faculty of Mechanical Engineering at the Universiti Teknologi Malaysia for their support and cooperation during this study. The authors also wish to thank Research Management Centre (RMC) for the Research University Grant (02G34, 02G35, 09H64) from the Universiti Teknologi Malaysia and Fundamental Research Grant Scheme (4F610) from the Ministry of Higher Education for their financial support.

\section{References}

1. Richard, E.B., Tribology Data Handbook: An Excellent Friction, Lubrication and Wear Resource, CRC Press, United Kingdom (1997).

2. Kuzman, K., Encyclopedia of Materials: Science and Technology, 2nd Edn., McGraw Hill, United States (2001).

3. Neil, C. "Challenges in formulating metal forming fluids", http://www.stle.org (2009). Accessed October 21, 2014.

4. Gariety, M., Ngaile, G. and Altan, T. "Evaluation of new cold forging lubricants without zinc phosphate precoat", Int. J. of Machine Tools and Manufac., 47, pp. 673-681 (2007).

5. Jung, K.H., Lee, H.C., Kang, H.C. and Im, Y.T. "Effect of surface roughness on friction in cold forging", J. of Ach. Mater. and Manufac. Engrg., 31(2), pp. 327334 (2008).

6. Křupka, I. and Hartl, M. "The effect of surface texturing on thin EHD lubrication films", Tribol. Int., 40(7), pp. 1100-1110 (2007). 
7. Babatunde, L.A. and Michael, B.A. "Evaluations of vegetable oil-based as lubricant for metal forming processes", Ind. Lubricat. Tribol., 60(5), pp. 242-248 (2008).

8. Syahrullail, S., Kamitani, S. and Nakanishi, K. "Experimental evaluation of refined, bleached, and deodorized palm olein and palm stearin in cold extrusion of aluminum A1050", Tribol. Transac., 55(2), pp. 199209 (2012).

9. Zhang, B., Wei, H., Jingqiu, W. and Xiaolei, W. "Comparison of the effects of surface texture on the surfaces of steel and UHMWPE", Tribol. Int., 65, pp. 138-145 (2013).

10. Gwidon, W.S. and Andrew, W.B., Lubricants and Their Composition, Engineering Tribology, 4th Edn., Elsevier, Oxford (2014).

11. Ilija, G. "Palm oil usage in lubricants", 3rd Global Oils and Fats Business Forum, United State of America, pp. 1-19 (2003).

12. Friends of the Earth "The use of palm oil for biofuel and as biomass for energy", Earth no. August 2006, pp. 1-4 (Accessed April 27, 2015).

13. Leslic, R.R. and Sevim, Z.E., Synthetic Mineral Oils and Biobased Lubricants, CRC Press, Taylor and Francis Group, p. 356 (2006).

14. Azizi, E., Anna, S. and Pascal, L. "Biofuels and the sustainability challenge: A global assessment of sustainability issues, trends and policies for biofuels and related feedstocks", Trade and Markets Division, Food and Agriculture Organization of the United Nations, Rome, Italy (2013).

15. Caminaga, C., da Silva Issii, R.L. and Button, S.T. "Alternative lubrication and lubricants for the cold extrusion of steel parts", J. of Mater. and Process. Technol., 179(1-3), pp. 87-91 (2006).

16. Caminaga, C., Neves, F.O., Gentile, F.C. and Button, S.T. "Study of alternative lubricants to the cold extrusion of steel shafts", J. of Mater. and Process. Technol., 182(1-3), pp. 432-439 (2007).

17. Shashidhara, Y.M. and Jayaram, S.R. "Vegetable oils as a potential cutting fluid-An Evolution", Tribol. Int., 43(5-6), pp. 1073-1081 (2010).

18. Arnsek, A. and Vizintin, J. "Lubricating properties of rapeseed based oils", J. of Synthetic Lubric., 16, pp. 281-296 (1999).

19. Li, Q., Smith, C.J., Harris, C. and Jolly, M.R. "Finite element investigations upon the influence of pocket die designs on metal flow in aluminum extrusion: Part I. Effect of pocket angle and volume on metal flow", $J$. of Mater. Process. Technol., 135, pp. 189-196 (2003).

20. Hong, T., Sakaa, N. and Suh, N.P. "Boundary lubrication studies on undulated titanium surfaces", STLE Tribol. Transac, 32, pp. 289-96 (1989).

21. Nilsson, B., Rosen, B., Thomas, T., Wiklund, D. and Xiao, L. "Oil pockets and surface topography: mechanism of friction reduction", XI International Colloqium Surfaces, Chemnitz (2004).
22. Syahrullail, S., Kamitani, S. and Nakanishi, K. "Experimental evaluation of refined, bleached, and deodorized palm olein and palm stearin in cold extrusion of aluminum A1050", Tribol. Transac., 55, pp. 199-209 (2012).

23. Lesniak, D. and Libura, W. "Extrusion of sections with varying thickness through pocket dies", J. of Mater. Process. Technol., 193, pp. 38-45 (2007).

24. Kamitani, S., Nakanishi, S., Syahrullail, S. and Seki, Y. "The effect of lubricants on material flow characteristic by plane strain extrusion with micro-pits formed on the tool surface", 9th International Conference of Technology Plastic - ICTP2008, Gyeongju, South Korea (2008).

25. Koszela, W., Pawlus, P. and Galda, L. "The effect of oil pockets size and distribution on wear in lubricated sliding", Wear, 263, pp. 1585-92 (2007).

26. Galda, L., Pawlus, P. and Sep, J. "Dimples shape and distribution effect on characteristics of Stribeck curve", Tribol. Int., 42(10), pp. 1505-1512 (2009).

27. Norhayati, A., Maizan, S., Zin, H.M., Wira, J.Y., Nik, W.B.W. and Syahrullail, S. "The influence of lubricant viscosity in cold work forward extrusion using micropits tool", J. Teknologi, 58, pp. 89-93 (2012).

28. Sudeep, U., Pandey, R.K. and Tandon, N. "Effects of surface texturing on friction and vibration behaviors of sliding lubricated concentrated point contacts under linear reciprocating motion", Tribol. Int., 62, pp. 198207 (2013).

29. Reizer, R., Galda, L., Dzierwa, A. and Pawlus, P. "Simulation of textured surface topography during a low wear process", Tribol. Int., 44(11), pp. 1309-1319 (2011).

30. Reizer, R., Pawlus, P., Galda, L., Grabon, W. and Dzierwa, A. "Modeling of worn surface topography formed in a low wear process", Wear, 278-279, pp. 94-100 (2012).

31. Bruce, R.W., Handbook of Lubrication and Tribology, Vol. II: Theory and Design, CRC Press (2012).

32. Noorani-Azad, M., Bakhshi-Jooybari, M., Hosseinipour, S.J. and Gorji, A. "Experimental and numerical study of optimal die profile in cold forward rod extrusion of aluminum", J. of Mater. Process. Technol., 164, pp. 1572-1577 (2005).

33. Liliang, W., Zhou, J., Duszczyk, J. and Katgerman, L. "Friction in aluminum extrusion - Part 1: A review of friction testing techniques for aluminum extrusion", Tribol. Int., 56, pp. 89-98 (2012).

34. Chiong, Ing. T., Rafiq, A.K.M., Azli, Y. and Syahrullail, S. "Tribological behaviour of refined, bleached and deodorized palm olein in different loads using a fourball tribotester", Scientia Iranica, 19(6), pp. 14871492 (2012).

35. Yingying, L., Houfang, L., We, J., Dongsheng, L., Shijie, L. and Bin, L. "Biodiesel production from crude Jatropha curcas L. oil with trace acid catalyst", Chi. J. of Chem. Engng., 20, pp. 740-746 (2012). 
36. Caminaga, C., Neves, F.O., Gentile, F.C. and Button, S.T. "Study of alternative lubricants to the cold extrusion of steel shafts", J. of Mater. Process. Technol., 182, pp. 432-439 (2007).

37. Syahrullail, S., Zubil, B.M., Azwadi, C.S.N. and Ridzuan, M.J.M. "Experimental evaluation of palm oil as lubricant in cold forward extrusion process", Int. J. of Mech. Sci., 53, pp. 549-55 (2011).

38. Wakuda, M., Yamauchi, Y., Kanzaki, S. and Yasuda, Y. "Effect of surface texturing on friction reduction between ceramic and steel materials under lubricated sliding contact", Wear, 254, pp. 356-63 (2003).

39. Masuko, M., Aoki, S. and Suzuki, A. "Influence of lubricant additive and surface texture on the sliding friction characteristics of steel under varying speeds ranging from ultralow to moderate", Tribol. Transac., 48, pp. 289-298. (2005).

40. Gang, F. and Zhou, J. "Effect of pocket design on metal flow through single-bearing extrusion dies to produce a thin-walled aluminium profile", J. of Mater. Process. Technol., 199, pp. 91-101 (2008).

41. Tiernan, P., Hillery, M.T., Draganescu, B. and Gheorghe, M. "Modelling of cold extrusion with experimental verification", J. of Mater. Process. Technol., 168, pp. 360-366 (2005).

42. Sudeep, U., Tandon, N. and Pandey, R.K. "Tribological studies of lubricated laser-textured point contacts in rolling/sliding reciprocating motion with investigations of wettability and nanohardness", Tribol. Transac., 58, pp. 625-634 (2015).

43. Solomon, N. and Solomon, I. "Effect of die shape on the metal flow pattern during direct extrusion process", Rev. de Met., 46(5), pp. 396-404 (2010).
44. Syahrullail, S., Azwadi, C.S.N., Abdul Kadir, M.R. and Shafie, N.E.A. "The effect of tool surface roughness in cold work extrusion", J. of Applied Sci., 11(2), pp. 367-372 (2011).

45. Mariana, P., Frunza, D.A.N. and Neag, A. "Experimental and numerical aspects regarding lead alloy plastic deformation", Rev. de Roumania Sci. Technol., 57(1), pp. 71-82 (2012).

46. Qamar, S.Z. "FEM study of extrusion complexity and dead metal zone", Arch. of Mater. Sci. and Engng., 36(2), pp. 110-117 (2009).

\section{Biographies}

Nurul Aini Mohd was born in Johor, Malaysia, in 1982. She received her bachelor degree in Mechanical Engineering in 2005 and Master Degree in Manufacturing Engineering in 2010. In 2007, she joined Polytechnic of Ibrahim Sultan as a Lecturer. She received her Doctor of Philosophy in Mechanical Engineering from University of Technology Malaysia in 2014. Her current research interests include tribological study, manufacturing process modification, and material properties study.

Syahrullai Samionl obtained his Doctor of Philosophy in Engineering from Kagoshima University, Japan, in 2007. His major field of study is tribology in metal forming. He is currently an Associate Professor at the Department of Thermofluids, Faculty of Mechanical Engineering, Universiti Teknologi Malaysia. His interests include development of bio-lubricant, palm oil research and fluid mechanics. 